\title{
Acesso à cultura: a "hora e a vez" dos projetos sociais democratizadores da cidadania cultural
}

\section{Access to culture: the right opportunity for the social projects that can democratize cultural citizenship}

\section{Acceso a la cultura:"el momento y la ocasión" de los proyectos sociales democratizadores de la ciudadanía cultural}

Sergio José Andreucci Júnior

Podemos refletir acerca das mais variadas questões, mas o objeto de estudo do presente depoimento visa ofertar uma análise da situação da cultura no país, e os meios necessários para sua democratização, especialmente tendo por público-alvo crianças e adolescentes.

Demonstraremos ao longo da incursão que projetos sociais implementados em parcerias com empresas, institutos, órgãos governamentais e a sociedade civil em geral são da mais absoluta importância para se garantir o que se denomina de cidadania cultural.

\section{CULTURA: UM CONCEITO NECESSÁRIO}

A sociedade ainda não tem uma percepção clara de que a difusão cultural, em todos os seus segmentos, é de extrema importância para o desenvolvimento social, político e econômico das pessoas.

1 Mestre em Comunicação pela Faculdade Cásper Líbero (FCL). MBA em Gestão Estratégica de Negócios pela Escola de Administração da Fundação Getúlio Vargas-SP. Pós-graduado em Administração de Marketing pela Fundação Álvares Penteado. Pós-graduado em Qualidade Total pela Universidade Federal de Minas Gerais (UFMG)-Fundação Christiano Otoni. Graduado em Relações Públicas pela FCL. Sócio-diretor da Agência de Publicidade Andreucci Comunicação. Professor do Curso de Relações Públicas da FCL. Professor convidado do Curso de Pós-Graduação em Comunicação e Mercado da ECA-USP. Diretor de Marketing da Cia. de Dança Cisne Negro. Diretor executivo dos projetos sociais "Caminhos da Arte" e "Reciclando sonhos". 
A busca de processos menos burocráticos que permitam o acesso à cultura e à educação são fundamentais para o desenvolvimento humano e para o crescimento do Brasil.

A política cultural não deve apenas dar acesso a obras culturais especificas, mas aos mais variados estilos e modelos de obras culturais, para que a partir daí os interessados possam fazer a escolha de acordo com seus gostos evitando assim serem condicionados por uma demanda já definida de projetos culturais. Muitas vezes não é que uma sociedade não admira determinado tipo de cultura, mas sim que não a conhece. Dessa forma a democratização garante o acesso à variedade sem excluir esse ou aquele tipo de manifestação cultural.

Somente em 1985, quando se restaurou a democracia no paós, surgiu o Ministério da Cultura (Minc), cujo objetivo era, e ainda é, fomentar e difundir a produção cultural no Brasil. Após a criação do ministério, surgem as primeiras leis federais que incentivaram a iniciativa privada a participar do setor cultural do Brasil. A Lei Sarney, de 1986, permitia a dedução de $2 \%$ do imposto de renda de pessoas jurídicas e de $10 \%$ do de pessoas físicas, que seriam transferidos para atividades culturais. Contudo, a não-exigência de uma apresentação prévia de projetos ao ministério, bastando apenas a transação direta entre empresas e produtores culturais, deu margem a desvios e fraudes, deteriorando a imagem do setor.

Em 1990, durante o governo Collor de Mello, o Ministério da Cultura foi rebaixado a Secretaria da Cultura, sendo, assim, subordinada ao presidente. A Fundação Nacional de Artes Cênicas (Fundacen), a Fundação do Cinema Brasileiro (FCB), a Embrafilme, a Fundação Nacional Pró-Leitura (FNPL) o Conselho Federal de Cultura (CFC) e o Conselho Consultivo de Secretaria do Patrimônio Histórico e Artístico Nacional (Sphan) foram extintos. Além disso, houve uma redução de quase $35 \%$ nos gastos públicos com cultura se comparado com o governo Sarney.

A fim de suprir a decadente situação da produção cultural do Brasil no início da década de 1990, o então secretário da Cultura, Sérgio Paulo Rouanet, criou uma nova lei federal de fomento ao setor. A conhecida Lei Rouanet (Lei n.8313, de 23/12/1991) redefinia os incentivos concedidos pela Lei Sarney e reorganizava o processo de aprovação dos projetos. Além disso, foi instituído o Fundo de Investimento Cultural e Artístico (Ficart) e foi restabelecido o Fundo Nacional de Cultura (FNC), antes conhecido como Fundo de Promoção Cultural. Todas essas medidas ainda são utilizadas até hoje, porém a sociedade e governo já debatem um novo modelo que resultará em uma nova política de incentivo á cultura.

Em 1995, já no governo Fernando Henrique Cardoso, parte da verba publicitária dos ministérios e das empresas públicas era destinada a projetos culturais. A partir desse período, o governo facilitou ainda mais as ações culturais, ga- 
rantindo grande envolvimento dos setores públicos e privados. Novas leis de isenção fiscal foram criadas em todo o Brasil (nos âmbitos federais, estaduais e municipais) e muitas empresas adotaram o incentivo à cultura como estratégia da comunicação. Isso resultou em uma grande expansão da área, garantindo cada vez mais entretenimento e cultura à população brasileira.

Já na era Luiz Inácio Lula da Silva, é lançada uma política cultural de governo partindo de diferentes experiências das administrações populares de cidades governadas pelo Partido dos Trabalhadores (PT) em todas as regiões do país, grupos culturais e a reflexão dos estudiosos das questões da cultura, munidos de algumas convicções firmadas no programa de governo do presidente Lula:

A valorização da cultura nacional é um elemento fundamental no resgate da identidade do país. É preciso, pois, abrir espaço para a expressão de nossas peculiaridades culturais (inclusive de corte regional), sem que isso se confunda com um nacionalismo estreito, mas sim articulado e aberto às culturas de todo o mundo. Trata-se, na linha de nossa melhor tradição cultural, de resgatar os traços peculiares de nossa identidade em formas de expressão de cunho universal, isto é, em diálogo aberto com todo mundo. É essencial, nessas condições, realizar um amplo processo de inclusão cultural, garantindo, de forma progressiva, o acesso de toda a cidadania à produção e fruição cultural, bem como a livre circulação de ideias e de formas de expressão artística. ${ }^{1}$

Segundo o Ministério da Cultura, a cultura está presente em todas as ações da sociedade. A resignação ou o inconformismo com que o cidadão encara sua realidade é, sobretudo, uma conduta cultural. O próprio fato de o indivíduo se perceber como cidadão é fruto de condicionantes culturais e históricas. Uma ação de governo que se pretenda progressista, ou transformadora, tem a cultura como prioridade. Democratizar a cultura é democratizar o acesso aos bens da cultura universal, permitindo que as pessoas se elevem à autoconsciência de sua participação no gênero humano. Ampliar o raio de ação das obras culturais, e não adaptá-las, moldá-las, enfraquecê-las, permite que o indivíduo se aproprie de instrumentos capazes de romper a falsa consciência alienada e particularista que o impede de desenvolver uma postura crítica diante do mundo em que vive.

Vista desse modo, a cultura deixa de ser um bem secundário em um país de tantas carências e passa a ser um bem social, assim como as áreas de saúde e educação. Por esses motivos, uma gestão pública de cultura deve ser entendida como prioritária e social, como alavanca de transformações.

Vivemos cada vez mais em uma sociedade onde informação é poder. Romper com a alienação e o embrutecimento imposto a amplas parcelas da população é, efetivamente, desenvolver uma política democrática, de conquista da cidadania, o que significa prever uma ampla e pluralista oferta de produtos cultu-

1 Item 35 das Concepções e Diretrizes do Programa de Governo do PT para o Brasil. 
rais. Manter a população no campo de uma cultura "rasa" é o melhor caminho para subjugá-la. Para romper com esse quadro, é necessário "depurar" o "senso comum" elevando a interpretação da cultura a uma concepção de mundo mais organizada e sistemática, colocada à altura da modernidade.

A cultura é um instrumento de relações sociais e se manifesta na criação artística, nunca é supérflua e o trabalho a ela destinado nunca é inútil, representando o espelho da alma humana. Quanto maior for o domínio de análise simbólica que as pessoas têm sobre a produção social, maior será a sua capacidade de articulação na sociedade.

Ao Estado compete assegurar, sem censura, total liberdade de manifestação e expressão. A criação, mesmo acontecendo em qualquer lugar e em todas as atitudes da sociedade, necessita de espaços próprios para se realizar plenamente. Uma gestão pública da cultura deve articular a abertura e manutenção desses espaços.

A cultura permeia todas as ações da sociedade e, por consequência, todos os programas de governo. Cultura como visão de governo gera renda, é social, amplia os horizontes, é comportamento, se manifesta nas mínimas relações do cotidiano, é postura frente ao mundo.

\section{CULTURA E RESPONSABILIDADE SOCIAL}

Devido ao processo de globalização, fortemente acelerado pelos meios de comunicação de massa, a sociedade contemporânea sofreu profundas transformações ideológicas e econômicas. As políticas neoliberais promoveram ampliação de mercados e a concorrência tornou-se mais acirrada. Com o tempo, as inovações tecnológicas deixaram de ser os diferenciais na escolha do produto e as marcas adquiriram grande importância no processo de conquista de clientes.

Aquilo que existe entre o engajamento de uma empresa em projetos culturais e a sua vontade de contribuir para a sociedade na qual atua motivou boa parte do início dos envolvimentos empresariais com o setor cultural.

A fim de estabelecer empatias e diferenciações em relação ao público consumidor, as organizações procuraram vínculos e compromissos com as culturas locais. Buscavam algo mais que visibilidade e resultados imediatos: buscavam consolidar seu posicionamento no mercado por meio da ética e de uma boa imagem.

Foi então que visualizaram a importância de implementar projetos comprometidos com o desenvolvimento humano e social, propondo ações concretas para a sociedade. 
A conscientização do papel das organizações na sociedade respondeu não apenas às necessidades da concorrência, como também às cobranças da sociedade. Os próprios cidadãos, incentivados pela mídia, exigiam uma nova postura das organizações. A partir da década de 1990, não bastava que as empresas oferecessem empregos e oportunidades de consumo. Era preciso mais comprometimento com a sociedade por meio da preservação do meio ambiente, da garantia de produtos seguros e de qualidade, de contribuições na educação e nas artes, de revitalizações de áreas urbanas, entre outras ações de responsabilidade social. Essa postura permanece até os dias atuais.

Na década de 1990 a responsabilidade social ganhou impulso e crescimento graças às discussões acerca da globalização e dos impactos que ela apresenta para a sociedade. No Brasil o termo se disseminou por meio das ONGs e da criação do Instituto de Análises Sociais e Econômicas (Ibase), fundado em 1981. Com esse instituto foi implantado no Brasil o conceito e as prática do balanço social, já conhecido e aplicado em diversos países.

Em 1998 surge o Instituto Ethos de Empresas e Responsabilidade Social. Tratase de uma organização não-governamental criada com a missão de mobilizar, sensibilizar e ajudar as empresas a gerir seus negócios de forma socialmente responsável, tornando-as parceiras na construção de uma sociedade sustentável. A difusão cultural é parte integrante para o desenvolvimento social da nação e, portanto, investimento fundamental dentro das premissas e dos conceitos da responsabilidade social.

Como o conceito de responsabilidade social é ainda novo para a sociedade organizacional brasileira, com cerca de dez anos, sofre muitas distorções. Diversas empresas acreditam que ações esporádicas na comunidade local as rotulam como socialmente responsáveis.

Assim, torna-se necessário incorporar as ações de responsabilidade social aos valores institucionais, compartilhando-as com os funcionários e outros públicos estratégicos das empresas. Busca-se um compromisso social efetivo e transparente, assumindo publicamente parcerias com projetos estruturados e realizados em longo prazo.

Não se deve, porém, romantizar o compromisso social das organizações modernas. O uso do balanço social como instrumento de gestão empresarial, por exemplo, muitas vezes demonstra o engajamento institucional com causas sociais e desconsidera obrigações implícitas às atividades. Além disso, as ações socialmente responsáveis encarecem o preço das mercadorias, uma vez que os custos de programas sociais são elevados, mesmo com o auxílio de algumas leis de incentivo.

A cultura é cada vez mais reconhecida como interventora do desenvolvimento social e, portanto, deve ser disponibilizada a todas as pessoas, independente- 
mente de classe social, etnia ou região em que vivem. O seu acesso está assegurado na Declaração Universal dos Direitos Humanos

Contudo, devido à grande quantidade de atividades e à falta de verbas, o Estado não consegue cumprir todas as tarefas com que se compromete, deixando de sanar algumas necessidades da população. Para extinguir essas carências, muitas organizações passam a atuar na sociedade, garantindo algo mais que seus produtos e serviços.

Claro que as organizações não assumem políticas culturais apenas como um compromisso social de agir com ética diante da sociedade. Também buscam espaço no competitivo mercado, envolvendo-se com seus públicos direto e indireto. Desse modo, passam a suprir suas necessidades de marketing e comunicação investindo nos projetos culturais, trabalhando o posicionamento da marca e apresentando-se como socialmente responsáveis.

Porém, é preciso cuidar para contornar a distorção do enfoque dos projetos culturais, transformando-os em demanda comercial e, assim, abandonar o compromisso de promover o desenvolvimento humano, proporcionando novas oportunidades de aprendizado, experiências e formação. O grande desafio dos profissionais do mercado cultural está, justamente, em harmonizar os interesses lucrativos e o interesse social.

\section{CRIANCCAS E ADOLESCENTES "FAZENDO ARTE": PROJETOS SOCIAIS DEMOCRATIZADORES DA CULTURA}

A arte é de suma importância para o homem, pois somos seres linguísticos, que se expressam por meio de diversas linguagens - oral, visual, corporal.

Desde os primórdios dos tempos, o homem é o único ser vivente capaz de lembrar o passado, viver presente e imaginar o futuro.

Assim, por meio das diversas manifestações artísticas, o ser humano capacitase para um futuro melhor e mais promissor, conhecendo o seu passado, intrínseco nas mais diversas artes (dança, música, literatura, artes plásticas, etc.), aprendendo a viver e a modificar o seu presente. Dessa forma, ele se prepara para atuar num mercado de trabalho globalizado, no qual não basta a ele apenas ser competente, mas é preciso tornar o seu desempenho diferenciado, à medida que avalia e atua para modificar e adaptar-se às necessidades que se apresentam a cada momento de sua vida, desenvolvendo suas potencialidades por meio da criatividade.

Os projetos sociais elaborados por meio de parcerias cumprem o papel de levar a cultura e a arte a crianças e jovens de menor poder aquisitivo, garantindo seu acesso aos bens culturais e o fortalecimento de sua cidadania. 
Neste tópico pretendemos apresentar duas experiências de sucesso que partem da tradição em arte e cultura da Cisne Negro Cia. de Dança, uma companhia paulistana com 33 anos de história, de renome nacional e internacional e marcada notadamente pela seriedade, pela dedicação e pelo compromisso no enaltecimento da arte e da cultura no Brasil.

"Caminhos da arte", projeto de iniciação profissional elaborado pela Cisne Negro Cia. de Dança com patrocínio da Monsanto Imagine ${ }^{1}$, visa contribuir para o desenvolvimento dos jovens pertencentes ao bairro da Vila Madalena e das adjacências, na cidade de São Paulo.

O projeto oferece a esses jovens a possibilidade do desenvolvimento socioeconômico e cultural, criando a oportunidade para que eles desenvolvam suas potencialidades, ampliando a visão de mundo, valorizando suas raízes culturais, aumentando sua autoestima e conscientizando-os do seu papel de cidadãs e cidadãos na sociedade. A participação nesse projeto proporciona o aumento da segurança e consciência de suas próprias capacidades, transformando-os em agentes multiplicadores dos conhecimentos adquiridos, contribuindo dessa forma para o desenvolvimento de sua família e de sua comunidade.

O projeto, por meio da arte e da formação moral e cívica, tem por finalidade contribuir para o desenvolvimento pessoal, artístico, moral e social dos jovens, da comunidade com idade entre 13 e 16 anos, despertando suas potencialidades e ampliando suas chances de inserção no mercado de trabalho.

As atividades apresentadas pelo projeto visam, entre outros objetivos, a:

- Resgatar a autoestima dos jovens e melhorar a capacidade de se comunicar, de conviver, de respeitar as diferenças individuais e culturais, de amar e lutar pela cidadania plena;

- Possibilitar aos jovens a percepção do trabalho como realização pessoal e meio de transformação do mundo, facilitando o seu ingresso no mercado de trabalho;

- Proporcionar ao jovem, durante o seu tempo fora da escola, atividades de formação moral, cultural e profissional.

As ações do projeto estão relacionadas a educação ambiental, cidadania, artes, artes cênicas, música, dança, palestras, oficinas e outras atividades.

Também como parceria da Cia. Cisne Negro de Dança e com o patrocínio do Grupo Fleury², existe a experiência do projeto denominado "Reciclando so-

1 A Monsanto encontra-se no Brasil desde 1951, com sede em São Paulo, voltando-se para a produção de herbicidas e sementes de milho, soja, algodão e hortaliças, além de variedades de cana-de-açúcar, tendo por objetivo a produção com tecnologia.

20 Grupo Fleury é uma organização atuante em medicina diagnóstica no Brasil, com mais de 150 unidades de atendimento, presentes noseEstados de São Paulo, Rio de Janeiro, Bahia, Pernambuco, Paraná e Rio Grande do Sul, além de Brasília. 
nhos", traduzido como um projeto de arte-educação e complementação escolar.Destina-se a jovens de 12 a 16 anos, provenientes de comunidades de baixa renda, visando, por meio da dança, da música e das artes em geral, e abordando temas como preservação do meio ambiente, reciclagem, saúde, higiene, entre outros, contribuir para a formação e o exercício pleno de sua cidadania, além de permitir-lhes vislumbrar a possibilidade de uma futura profissão dentro das artes cênicas, como artistas, técnicos ou prestadores de serviços.

O projeto "Reciclando sonhos", realizado na região do bairro do Jabaquara, na capital paulista, em espaço cedido pelo Centro Assistencial Cruz de Malta, visa conscientizar os jovens quanto a conceitos e causas que causem impacto positivo nas comunidades atendidas, além de complementar a formação escolar. escolar.Entre os objetivos almejados, podemos citar:

- Conscientização da importância da coleta seletiva de lixo, reciclagem e preservação do meio ambiente, com a transformação dos materiais coletados em arte;

- Causar impacto na comunidade em que vivem e, consequentemente, na sociedade;

- Desenvolver a consciência coletiva e sua importância como forma de integração social e do exercício pleno da cidadania;

- Proporcionar complementação escolar por meio da dança, da música, de artes plásticas, palestras, workshops e oficinas, atividades que são coordenadas por profissionais experientes e devidamente capacitados em cada área.

Neste final de 2010, como resultado dos trabalhos desenvolvidos, foi apresentado o espetáculo "Reciclando sonhos", projetado e construído pelos participantes do projeto em seus laboratórios e a partir de suas vivências no decorrer das atividades regulares do ano. Os participantes produziram os cenários, figurinos e adereços com materiais reciclados, fazendo com que os jovens, além de se envolverem no processo de criação e montagem da peça, também contribuíram para a limpeza da comunidade onde moram e a preservação do meio ambiente, fomentando assim uma consciência de bem-estar, autoestima e exercício pleno da cidadania.

Importante mencionar que a Cisne Negro Cia. de Dança desenvolve um programa de formação de bailarinos, os quais ingressam como bolsistas, passam a Estagiários e, posteriormente, se vinculam ao elenco fixo da companhia. Assim, como forma de incentivo e motivação os alunos do projeto que mais se destacarem nas áreas de dança e afins serão incorporados na Cisne Negro Cia. de Dança como estagiários ou bolsistas, sendo-lhes proporcionada uma nova profissão.

Por fim, a exemplo da Cisne Negro Cia. de Dança, temos dezenas de experiências bem-sucedidas por todo o Brasil, demonstrando que não basta apenas a vontade e a política escrita, mas se faz necessário o exercício de atitudes transformadoras que possibilitem um futuro melhor para a sociedade e para o mercado cultural brasileiro. 